\title{
Stres Kerja dan Lingkungan Kerja dalam Mempengaruhi Komitmen Organisasi Karyawan STIE Rahmaniyah Sekayu
}

\author{
Emelda \\ STIE Rahmaniyah Sekayu \\ imeldaoedirman@yahoo.com
}

\begin{abstract}
ABSTRAK
Tujuan penelitian ini untuk mengetahui pengaruh Stres Kerja dan Lingkungan Kerja teerhadap Komitmen Organisasi Karyawan STIE Rahmaniyah Sekayu". Model analasis menggunakan analisis regresi linear berganda melalui uji asumsi klasik yaitu uji normalitas data, uji heterokedastisitas dan uji autokorelasi. Jawaban angket sebanyak 32 responden di uji dengan uji validitas dan uji reliabilitas. Hasil penelitian variabel stres kerja diperoleh nilai sebesar $0,034<$ signifikan $\alpha=0,05$ artinya terdapat pengaruh sinifikan dan positif stres kerja terhadap komitmen organisasi. Nilai signifikan variabel lingkungan kerja sebesar $0,017<$ nilai signifikan $\alpha=0,05$ artinya terdapat pengaruh signifikan dan positif lingkungan kerja terhadap komitmen organisasi karyawan STIE Rahmaniyah Sekayu.
\end{abstract}

Kata Kunci : Stres Kerja, Lingkungan Kerja dan Komitmen Organisasi

\section{A. PENDAHULUAN}

Sumber daya manusia merupakan salah satu elemen organisasi yang berperan besar bagi suatu perusahaan atau instansi untuk pencapaian suatu tujuan organisasi. Kecanggihan sarana dan prasarana yang dimiliki perusahaan atau instansi pemerintahan tanpa ditunjang dengan kemampuan pegawai tidak akan berjalan maksimal. Sumber daya manusia merupakan aset yang paling penting dalam mendukung pencapaian tujuan suatu instansi. Pencapaian tujuan instansi umumnya terletak pada upaya bagaimana instansi menggunakan sumber-sumber yang dimilikinya menjadi berdaya guna.

Di dunia kerja, komitmen seseorang terhadap organisasi atau perusahaan sangat penting terutama pada penilaian kinerja seseorang dalam bekerja. Setiap perusahaan menginginkan karyawannya memiliki komitmen yang tinggi dalam bekerja. Komitmen tinggi menunjukkan keyakinan dan dukungan serta loyalitas seseorang terhadap nilai dan sasaran yang ingin dicapai organisasi. Komitmen organisasi yang kuat akan menyebabkan tiap individu berusaha mencapai tujuan organisasi, berpikir positif dalam organisasi akan merasa ikut memiliki organisasi. Organisasi yang memiliki karyawan berkomitmen rendah akan mengakibatkan sulitnya tercapai kinerja tinggi.

Permasalahan yang ditimbulkan rendahnya komitmen karyawan suatu perusahaan tidak terlepas dari lingkungan kerja karena merupakan salah satu faktor penting yang mempengaruhi perusahaan dalam tujuan, lingkungan kerja secara fisik dan non fisik juga mempengaruhi komitmen organisasi. Misalnya persepsi para karyawan mengenai lingkungan kerja yang mereka peroleh dapat memberikan penilaian yang berbeda atas segala aspek dari lingkungan kerja. Apabila persepsi yang ditunjukkan karyawan baik maka akan mempengaruhi kinerja karyawan maka karyawan akan merasa nyaman dan merasa senang berada dalam lingkungan kerja yang baik, sebaliknya 
jika karyawan memiliki persepsi buruk terhadap lingkungan kerja maka kinerja karyawan juga akan rendah dan keadaan tersebut akan mengurangi komitmen organisasi (Wang,et al: 2014).

Faktor lain yang mempengaruhi yang mempengaruhi komitmen organisasi adalah stres kerja. Stres kerja adalah proses psikologis yang tidak menyenangkan yang terjadi sebagai respon tekanan lingkungan kerja (Robbins \& Judge, 2015). Penanggulangan stres kerja bagi individu sangat penting dilakukan karena stres dapat mempengaruhi kehidupan, kesehatan dan produktivitas karyawan.

Berdasarkan latar belakang yang diuraikan diatas maka peneliti tertarik untuk melakukan kajian lebih mendalam melalui sebuah penelitian berjudul " Stres Kerja dan Lingkungan Kerja dalam Mempengaruhi Komitmen Organisasi Karyawan STIE Rahmaniyah Sekayu"

\section{B. KAJIAN PUSTAKA \\ 1) Stres Kerja}

Siagian (2016), menyatakan stress kerja merupakan kondisi ketegangan yang berpengaruh terhadap emosi, jalan pikiran, dan kondisi fisik seseorang. Selanjutnya Sinambela (2017), menyatakan bahwa stres kerja merupakan kondisi ketegangan yang berpengaruh terhadap emosi, jalan pikiran, dan kondisi fisik seseorang. Surya dalam Triatna (2015), menyatakan bahwa stres kerja merupakan suatu keadaan dimana seseorang mengalami ketegangan karena adanya kondisi yang mempengaruhi dirinya.

\section{2) Lingkungan Kerja}

Siagian (2016) lingkungan kerja adalah lingkungan dimana pegawai melakukan pekerjaannya sehari-hari".
Lingkungan Kerja yang kondusif memberikan rasa aman dan memungkinkan para pegawai untuk dapat bekerja optimal. Lingkunga kerja dapat mempengaruhi emosi pegawai. Jika pegawai menyenangi lingkungan kerja dimana dia bekerja, maka pegawai tersebut akan betah ditempat kerjanya untuk melakukan aktivitas sehingga waktu kerja dipergunakan secara efektif dan optimis prestasi kerja pegawai juga tinggi. Lingkungan kerja tersebut mencakup hubungan kerja yang terbentuk antara sesama pegawai dan hubungan kerja antar bawahan dan atasan serta lingkungan fisik tempat pegawai bekerja. Sementara Sedarmayanti, (2011) membagi lingkungan kerja menjadi dua bagian, lingkungan kerja non fisik". Lingkungan kerja fisik adalah semua keadaan berbentuk fisik yang terdapat disekitar tempat kerja yang dapat mempengaruhi karyawan baik secara langsung maupun secara tidak langsung. Lingkungankerja fisik dapat dibagi dalam dua kategori, yakni :

a) Lingkungan yang langsung berhubungan dengan karyawan (seperti: pusat kerja, kursi, meja dan sebagainya),

b) Lingkungan perantara atau lingkungan umum dapat juga disebut lingkungan kerja yang mempengaruhi kondisi manusia, misalnya: temperatur, kelembaban, sirkulasi udara, pencahayaan, kebisingan, getaran mekanis, bau tidak sedap, warna dan lain-lain. Untuk dapat memperkecil pengaruh lingkungan fisik terhadap karyawan, maka langkah pertama adalah harus mempelajari manusia, baik mengenai fisik dan tingkah lakunya maupun mengenai fisiknya, kemudian digunakan sebagai dasar memikirkan lingkungan fisik yang sesuai. Lingkungan kerja non fisik adalah semua keadaan yang terjadi 
yang berkaitan dengan hubungan kerja, baik hubungan denganatasan maupun hubungan sesama rekan kerja, ataupun hubungan dengan bawahan.

\section{3) Komitmen Organisasi}

Robbins (2016), menyatakan bahwa komitmen organisasi adalah keadaan dimana seorang pegawai memihak pada suatu organisasi tertentu dan tujuan-tujuan pegawai serta berniat memelihara keanggotaan dalam organisasi tersebut. Komitmen organisasi menjadi hal yang penting bagi perusahaan agar dapat berjalan kearah yang telah ditetapkan, sikap loyalitas kerja terhadap organisasinya dan juga merupakan suatu proses mengekspresikan perhatian dan partisipasinya terhadap organisasi. Colquitt et al. (2011) menjelaskan bahwa karyawan yang berkomitmen merupakan karyawan memiliki keinginan kuat untuk bertahan menjadi anggota organisasi.

Berikut ini variabel penelitian yang digambarkan dalam kerangka berpikir atau model penelitian dengan hipotesis yang akan dilakukan pembuktian lebih lanjut.

Gambar 1

Kerangka Berpikir

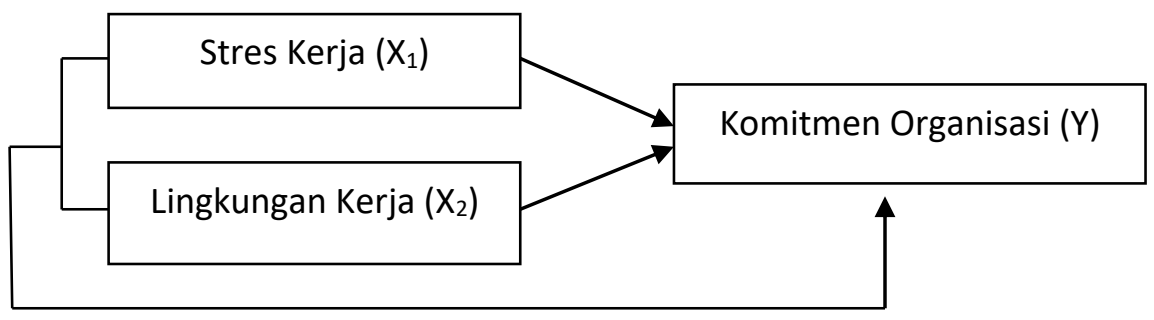

Berdasarkan kerangka penelitian di atas, maka hipotesis penelitian dalam penelitian ini adalah sebagai berikut:

$\mathrm{H} 1$ : Terdapat pengaruh signifikan dan positif stres kerja terhadap komitmen organisasi

$\mathrm{H}$ 2: Terdapat pengaruh signifikan dan positif lingkungan kerja terhadap komitmen organisasi

\section{METODE PENELITIAN}

Penelitian ini adalah penelitian kausalitas dengan menetapkan karyawan sebagai populasi penelitian berjumlah 32 orang sekaligus dijadikan sampel penelitian. Teknik pengambilan sampel non probability sampling yaitu sampel jenuh. Menggunakan skala likert untuk mengukur variabel-variabel dalam penelitian. Data yang dikumpulkan menggunakan kuisioner yang diberikan langsung kepada responden. Berikut ini adalah indikator penelitian adalah sebagai berikut:

Tabel 1

Definisi Operasional Variabel

\begin{tabular}{|c|c|l|l|}
\hline No & Variabel & \multicolumn{1}{|c|}{ Indikator } \\
\hline 1 & Stres Kerja & Kondisi yang mempengaruhi & 1. Tuntutan Tugas \\
& $($ X1) & emosi, proses berfikir, dan & 2. Tuntutan Peran \\
& & kondisi seseorang, stres yang & 3. Tuntutan Hubungan \\
& & terlalu berat akan mengancam & Pribadi \\
& & kemampuan seseorang dalam & 4. Struktur Organisasi \\
\hline
\end{tabular}




\begin{tabular}{|c|c|c|c|}
\hline & & mengahadapi lingkungannya. & $\begin{array}{l}\text { 5. Kepemimpinan } \\
\text { Organisasi }\end{array}$ \\
\hline 2 & $\begin{array}{l}\text { Lingkungan Kerja } \\
(\mathrm{X} 2)\end{array}$ & $\begin{array}{lr}\text { Lingkungan dimana pegawai } \\
\text { melakukan } \\
\text { sehari-hari }\end{array}$ & $\begin{array}{l}\text { 1. Penerangan } \\
\text { 2. Suhu Udara } \\
\text { 3. Suara Bising } \\
\text { 4. Penggunaan Warna } \\
\text { 5. Ruang Gerak } \\
\text { diperlukan } \\
\text { 6. Keamanan kerja } \\
\text { 7. Hubungan } \\
\text { Karyawan }\end{array}$ \\
\hline 3 & $\begin{array}{c}\text { Komitmen } \\
\text { Organisasi (X3) }\end{array}$ & $\begin{array}{l}\text { adalah keadaan dimana } \\
\text { seorang pegawai memihak } \\
\text { pada suatu organisasi tertentu } \\
\text { dan tujuan-tujuan pegawai } \\
\text { serta berniat memelihara } \\
\text { keanggotaan dalam organisasi } \\
\text { tersebut }\end{array}$ & $\begin{array}{l}\text { 1. Komitmen Afektif } \\
\text { 2. Komitmen Kontinyu } \\
\text { 3. Komitmen } \\
\text { Norvative }\end{array}$ \\
\hline
\end{tabular}

Dalam metode analisis data ini diuraikan mengenai teknik pengujian kuesioner dan teknik analisis data sebagai berikut:

1. Teknik pengujian kuesioner

a. Uji Validitas

Uji validitas digunakan untuk mengetahui sah atau Uji Validitas Uji validitas digunakan untuk mengetahui sah atau tidaknya suatu kuesioner. Suatu kuesioner dinyatakan valid jika pertanyaan pada kuesioner mampu mengungkapkan sesuatu yang akan diukur oleh kuesioner tersebut (Ghozali,2011). Taraf signifikasi ditentukan 5\%. Jika diperoleh hasil korelasi yang lebih besar dari $r$ tabel pada taraf signifikansi 0,05 berarti butir pertanyaan tersebut valid.

b. Uji Reliabilitas

Uji reliabilitas dalam penelitian ini menggunakan koefisien korelasi Spearman Brown. Instrumen dikatakan valid jika $\mathrm{t}$ hitung $>\mathrm{t}$ tabel Perhitungan koefisien korelasi dapat menggunakan alat bantu program computer yaitu SPSS versi 20 . c. Teknik Analisa Data

Analisis untuk mengetahui pengaruh kepemimpinan transformasional, motivasi, lingkungan kerja, etika kerja dan kompentensi terhadap komitmen kerja karyawa perusahaan.

1) Analisis Regresi Linier Berganda

Analisis ini untuk mengetahui pengaruh suatu variabel komitmen dihubungkan dengan variabel kepemimpinan transformasional, motivasi, lingkungan kerja, etika kerja dan kompetensi.

$$
\begin{aligned}
\mathrm{Y}=\mathrm{a}+ & \mathrm{b}_{1} \mathrm{X}_{1}+\mathrm{b}_{2} \mathrm{X}_{2}+\mathrm{b}_{3} \mathrm{X}_{3}+\mathrm{e} . \\
\hline \text { Dimana: } & \\
\mathrm{Y} \quad= & \text { Komitmen kerja } \\
\mathrm{a}= & \text { Konstanta } \\
\mathrm{X}_{1}= & \text { Stres Kerja } \\
\mathrm{X}_{2}= & \text { Lingkungan kerja } \\
\mathrm{b} \quad= & \text { Koefisien regresi yaitu } \\
& \text { besarnya perubahan yang } \\
& \text { terjadi pada jika satu unit } \\
& \text { perubahan pada variabel } \\
& \text { bebas (variabel } \mathrm{x}) \\
\mathrm{e} \quad & \text { Kesalahan prediksi }
\end{aligned}
$$


2) Uji Koefisien Regresi (Uji t)

Menunjukkan nilai signifikan dari tiap-tiap koefisien regresi terhadap kenyataan yang ada. $\mathrm{HO}$ diterima bila $\mathrm{t}$ tabel $\geq \mathrm{HO} \mathrm{t}$ hitung $>\mathrm{t}$ tabel

$\mathrm{H} 0$ ditolak bila t hitung $\leq \mathrm{t}$ tabel atau $<$ t hitung $<\mathrm{t}$ tabel

3) Uji Anova (Uji F)

Digunakan untuk mengetahui signifikasi pengaruh antara lima variable bebas (kepemimpinan transformasional, motivasi, lingkungan kerja, etika kerja dan kompentensi) terhadap variabel terikat (komitmen kerja) secara bersama-sama, sehingga bisa diketahui apakah dengan variabel yang sudah ada dapat diterima atau ditolak.

$\mathrm{H} 0$ diterima bila $\mathrm{F}$ tabel $\geq \mathrm{H} 0 \mathrm{~F}$ hitung $>\mathrm{F}$ tabel

$\mathrm{HO}$ ditolak bila $\mathrm{t}$ hitung $\leq \mathrm{F}$ tabel atau $<\mathrm{F}$ hitung $<\mathrm{F}$ tabel

\section{HASIL PENELITIAN}

Dari hasil pengolahan data karakteristik responden jenis kelamin laki-laki sebanyak 19 orang atau 59\% dan perempuan 12 orang atau $37 \%$. Karakteristik pendidikan karyawan dominan S1 yaitu sebanyak 21 orang atau $65,6 \%$ pendidikan D3 sebanyak 9 orang atau $28,2 \%$ dan sisanya 2 orang atau $6,2 \%$ berpendidikan SMA. Deskripsi variabel penelitian dapat dilihat pada tabel berikut:

Tabel 2

Deskripsi Variabel

\begin{tabular}{|l|c|c|c|c|c|c|}
\hline & $\mathrm{N}$ & Minimum & Maximum & Mean & Median & Std.Deviation \\
\hline $\mathbf{X 1}$ & 32 & 9 & 19 & 17,14 & 19,50 & 1,278 \\
\hline $\mathbf{X 2}$ & 32 & 11 & 17 & 15,68 & 17,00 & 1,100 \\
\hline $\mathbf{Y}$ & 32 & 15 & 20 & 21,23 & 24,00 & 1,565 \\
\hline
\end{tabular}

Sumber: Hasil Pengolahan Data Primer

Tabel 3

Hasil Uji Anova

\begin{tabular}{|c|l|c|c|c|c|c|}
\hline Model & & Sum of & df & Mean & F & Sig. \\
\hline 1 & Regression & 38.301 & 2 & 23.168 & 13.714 & $.000 \mathrm{a}$ \\
& Residual & 69.123 & 30 & 1.201 & & \\
& Total & 97.424 & 31 & & & \\
\hline
\end{tabular}

Hasil perhitungan Tabel Anova menunjukkan bahwa nilai $F$ hitung sebesar 13,714 dengan tingkat kesalahan atau probabilitas sebesar 0,00 yang berarti lebih kecil dari 0,05 $(0,000<0,05)$. Disimpulkan nilai $F$ hitung digunakan untuk menguji keepatan model (goodness of fit), dengan membandingkan $F$ hitung dengan $\mathrm{F}$ Tabel dengan derajat $(\mathrm{dfl})=$ $\mathrm{k}-1$ dan (df2) $=\mathrm{n}-\mathrm{k}$. Berikut hasil uji koefisien korelasi dan determinasi untuk masing-masing variabel : 
Tabel 4

Hasil Uji Koefisien Korelasi dan Determinasi

\begin{tabular}{|c|c|c|c|c|c|}
\hline Model & $\mathrm{R}$ & $\mathrm{R}$ & $\begin{array}{c}\text { Adjusted R } \\
\text { Square }\end{array}$ & $\begin{array}{c}\text { Std. Error of } \\
\text { the Estimate }\end{array}$ & $\begin{array}{c}\text { Durbin- } \\
\text { Watson }\end{array}$ \\
\hline 1 & $0.656^{\mathrm{a}}$ & 0.467 & 0.660 & 1.14035 & 1.712 \\
\hline
\end{tabular}

Hasil uji koefisien dan determinasi menunjukkan hasil uji multiple $\mathrm{R}$ sebesar 0,656 atau sebesar $65,6 \%$. Artinya korelasi berganda antara stres kerja dan lingkungan kerja memiliki hubungan yang kuat terhadap komitmen organisasi ( $(Y)$ karena terletak diantara 0,50-0,699, Adjusted $\mathrm{R}$ Square menunjukkan hasil nilai sebesar 0,467 berarti komitmen organisasi dapat dijelaskan oleh variabel stres kerja dan lingkungan kerja sebesar 46,7\%. Untuk membuktikan uji hipotesis maka dilakukan pengujian koefisien $t$ atau ttest dengan menghitung nilai dari $t$ hitung dan membandingkan dengan signifikan alpha 0,05. Berikut hasil uji koefisien Regresi (uji $t$ dapat dilihat pada Tabel 5 :

Tabel 5

Hasil Uji Koefisien Regresi (uji t)

\begin{tabular}{|l|l|r|r|}
\hline \multicolumn{2}{|c|}{ Model } & & \\
\hline 1 & (Constant) & 2,397 & Sig. \\
\cline { 2 - 4 } & Stres Kerja & 1,785 & 0,001 \\
& Lingkungan Krj & 2,667 & 0,034 \\
\hline
\end{tabular}

Hasil pengujian regresi variabel $t$ untuk variabel stres kerja diperoleh nilai sebesar $0,034<$ signifikan $\alpha=$ 0,05 artinya terdapat pengaruh sinifikan dan positif stres kerja terhadap komitmen organisasi. Nilai signifikan variabel lingkungan kerja sebesar $0,017<$ nilai signifikan $\alpha=$ 0,05 artinya terdapat pengaruh signifikan dan positif lingkungan kerja terhadap komitmen organisasi karyawan STIE Rahmaniyah Sekayu.

\section{E. PEMBAHASAN}

Hasil penelitian menunjukkan bahwa komitmen organisasi mempunyai peranan penting bagi dalam kegiatan STIE dan berperan penting bagi individu serta karyawan STIE membentuk network/kerjasama, memupuk semangat kerja, dan menciptakan loyalitas pada organisasi.
Ditunjukkan data perhitungan pengujian regresi variabel $t$ untuk variabel stres kerja diperoleh nilai sebesar $0,034<$ signifikan $\alpha=0,05$ artinya terdapat pengaruh sinifikan dan positif stres kerja terhadap komitmen organisasi. Nilai signifikan variabel lingkungan kerja sebesar 0,017 < nilai signifikan $\alpha=0,05$ artinya terdapat pengaruh signifikan dan positif lingkungan kerja terhadap komitmen organisasi karyawan STIE Rahmaniyah Sekayu.

Hasil uji koefisien dan determinasi menunjukkan hasil uji multiple $\mathrm{R}$ sebesar 0,656 atau sebesar $65,6 \%$. Artinya korelasi berganda antara stres kerja dan lingkungan kerja memiliki hubungan yang kuat terhadap komitmen organisasi (Y) karena terletak diantara 0,50 - 0,699, Adjusted $\mathrm{R}$ Square menunjukkan hasil nilai 
sebesar 0,467 berarti komitmen organisasi dapat dijelaskan oleh variabel stres kerja dan lingkungan kerja sebesar $46,7 \%$.

Penelitian ini mendukung penelitian Kurniasari dkk menunjukkan bahwa lingkungan kerja mempunyai pengaruh terhadap komitmen organisasi karyawan Dinas Pasar Unit Pasar Tanjung Kabupaten Jember. Penelitian lqbal menunjukkan bahwa stres kerja mempengaruhi komitmen organisasi karyawan lembaga pendidikan. Namun bertentangan dengan penelitian Rahmawati, yang menyatakan bahwa stres kerja tidak berpengaruh terhadap komitmen organisasi Bank Rakyat Indonesia (BRI) karena karyawan tetap berkomitmen baik dalam bekerja walaupun tekanan kerja yang luar biasa, hal ini dikarenakan kompensasi dari lembaga memberikan kepuasan dalam diri karyawan.

\section{F. KESIMPULAN DAN SARAN}

1) Kesimpulan Hasil penelitian variabel stres kerja diperoleh nilai sebesar 0,034 < signifikan $\alpha=0,05$ artinya terdapat pengaruh sinifikan dan positif stres kerja terhadap komitmen organisasi. Nilai signifikan variabel lingkungan kerja sebesar 0,017< nilai signifikan $\alpha$ $=0,05$ artinya terdapat pengaruh signifikan dan positif lingkungan kerja terhadap komitmen organisasi karyawan STIE Rahmaniyah Sekayu.

2) Saran

Saran bagi STIE Rahmaniyah Sekayu hendaknya pimpinan bisa memanage SOP kerja karyawan agar mereka mampu bekerja sesuai target dan skala prioritas tanpa tekanan dan deadline. Untuk itu perlu dukungan lingkungan kerja yang nyaman dan kondusif, agar karyawan merasa betah dalam bekerja dan mencintai STIE serta berkomitmen untuk mencapai tujuan bersama.

\section{DAFTAR PUSTAKA}

Colquitt dkk., J.A., Jeffrey A. Lepine., Michael J. Wesson. 2011. Organizational Behavior $\left(2^{\text {nd }}\right.$ ed). New York: McGrawHill/Irwin.

Ghozali, Imam. 2011. Aplikasi Analisis Multivariate dengan Program IBM SPSS 23 Edisi 8. Semarang: Badan Penerbit Universitas Diponegoro.

Robbins, Stephen P \& Judge Timothy A. 2016. Perilaku Organisasi Edisi ke-15 Jakarta: Salemba Empat.

Sedarmayanti. 2011. Pengembangan Kepribadian Pegawai. Bandung: Mandar Maju

Siagian, Sondang P. 2016. Teori Pengembangan Organisasi, Edisi ke 1 Cetakan 7. Jakarta: Bumi Aksara

Wang, Xuelli, Lin Ma \& Mian Z. 2014 Leadeship and Agency Worket's Organizational Commitment: The Mediating Effect of Organizational Justice and Job Characteristic. Social behavior and Personality, Vol 42 No.1 pp. 25-3 